\title{
The genetic structure of populations of sexual and asexual Taraxacum (dandelions)
}

\author{
Jane Hughes and \\ A. J. Richards
}

\author{
Department of Plant Biology, \\ University of Newcastle upon Tyne NE1 7RU, U.K.
}

The genetic structure, as assessed by isozymes, is described for three populations of outbreeding sexuals, three populations of obligate agamosperms, and six accessions of inbreeding sexual Taraxacum. Fifteen loci in 10 isozyme systems were identified, and isozyme bands were previously shown to be allelic in sexual $\times$ sexual and were confirmed as allelic in sexual $\times$ agamosperm crosses. Sexual $\times$ agamosperm crosses gave rise to both diploid sexual and tetraploid agamospermous offspring. Eight loci were found to be monomorphic, or almost so, in outbreeding sexuals and the agamosperms. Six loci were polymorphic in sexual outbreeders and two of the agamosperm populations; the third agamosperm population was polymorphic at only four loci. For outbreeding sexuals, genotype frequencies were consistent with Hardy-Weinberg equilibria. For the agamosperm populations, 14 out of 16 polymorphic loci were invariably heterozygous. In outbreeding sexual populations nearly all individuals had different genotypes. For two agamospermous populations, all individuals had the same genotype. For the third, three genotypes occurred. For the agamosperms all offspring studied showed the maternal genotype. For four of the inbreeding sexual accessions, all of the original siblings showed the same genotype, and their offspring only had maternal genotypes. For the fifth, one locus was polymorphic, but only homozygotes occurred in either generation. The sixth inbreeding accession, which may be partially outbred, was heterozygous at two loci in one individual, and heterozygous at one locus in another. These loci segregated in the offspring. With respect to various measures of genetic variation, sexual outbreeders and agamosperms were similar for the proportion of loci polymorphic, but this was lower in the inbreeders. The number of alleles per locus were similar for the sexual outbreeders and agamosperms, but this was higher in the inbreeders. Twice as many loci per individual were heterozygous in the agamosperms as in the sexual outbreeders, but the proportion heterozygous in the inbreeders was very low. Genotypic diversity was very high in the sexual outbreeders, and very low in the agamosperms. It was also very low within accessions, but high between accessions for the inbreeders.

\section{INTRODUCTION}

Nearly all higher organisms have retained a capacity for sexual reproduction. In the flowering plants, a total absence of sexual reproduction is unusual. Even asexual reproduction by seed (agamospermy) is rarely obligate; as Asker (1979, 1980) has most recently emphasized, most agamosperms retain the potential for sexual reproduction. Even obligate agamosperms usually retain pollen with which they can father the seeds of coexisting sexuals.

Yet, asexuals have many theoretical advantages over sexuals, stressed by Maynard Smith (1978) among others. These include avoidance of "genetic load" (loss of coadapted genomes by recombination and segregation), maternal investment in maternal genotypes, savings of males (in unisexuals) and male expenditure (in hermaphrodites), and avoidance of the "cost of outcrossing" in hermaphrodites. Such advantages should select against sexual outcrossing, at least in a uniform environment. We must presume that the benefits of recombination, and of offspring variability in unpredictable environments, have selected for sexual reproduction during the history of most organisms.

Theoretical considerations concerning the role played by genotypic diversity in the evolutionary success of sexuality, and the apparent evolutionary failure of asexuality, have been hampered by a shortage of information as to the actual genetic structure of asexual populations of plants. Although overviews of the relationship between 
breeding system and genetic structure such as Hamrick et al. (1979) and Gottlieb (1981) largely fulfill predictions about sexual systems, they include little information on asexual systems. Usberti and Jain (1978) have investigated the facultatively agamospermous grass Panicum maximum, but the only studies we can trace on obligate agamosperms have been in Taraxacum by Ford and Richards (1985), and van Oostrum et al. (1985). Unfortunately the work by Lyman and Ellstrand (1984) is hampered by the absence of any taxonomic information. These studies, notably van Oostrum et al., fulfill the predictions as to the structure of populations of agamosperms. Figures for genotypic diversity (G) are very low, and for heterozygosity $(\mathrm{H})$ are high in comparison with typical outbreeding sexuals (although these authors do not in fact present these figures, they are readily calculated from the data provided).

However, measures of genetic variation based on isozymes cannot be realistically compared between studies. They will differ depending on the systems studied, the techniques used, and the genera employed.

We considered that if meaningful comparisons are to be made for genetic variation between sexuals and asexuals, it is necessary to compare exactly the same allozymes for the same loci by the same techniques, using closely related taxa in the same genus. To our knowledge, there is only one genus in which outbreeding sexuals (selfincompatible), inbreeding sexuals (self-compatible), facultative agamosperms and obligate agamosperms all occur in related taxa. This is Taraxacum, a large, successful and weedy genus with 2000 species native to five continents, over large areas of which only obligate agamosperms persist (Richards, 1973, 1986).

We considered it essential that the isozymes studied were genetically characterized as allozymes. The inheritance of 20 loci in 12 systems has been characterized in a population of sexual outbreeders (Hughes and Richards, 1985). A later study investigated the inheritance of isozymes in agamosperm (male) $\times$ sexual crosses, and this is reported in this paper. Nearly all allozymes studied in agamosperm populations prove to be homologous with those in the sexual populations studied.

In the present study, 15 loci are studied in single populations of three agamospecies and three outbreeding sexual populations; and for six accessions of inbreeding sexuals belonging to four species. Phylogenetic aspects of the data obtained will be considered in a later paper.

\section{MATERIALS AND METHODS}

For the following populations, every plant was sampled (except for Au1), or all individuals within populations were sampled within circumscribed areas; plants were dug up and transplanted into $12 \mathrm{~cm}$ plastic pots, and grown on under glass at $15^{\circ} \mathrm{C}$ at a 12 hour day before isozyme analysis.

Taraxacum pseudohamatum Dahlst. T. sect. Hamata. $45 / 240657$, Newcastle upon Tyne, U.K. Urban roadverge. $2 n=24$. Obligate agamosperm. $N=45$.

Taraxacum unguilobum Dahlst. $T$. sect. Celtica. 35/927644, Hexham, U.K. Suburban garden. $2 n=32$. Obligate agamosperm, pollen absent. $N=30$.

Taraxacum brachyglossum (Dahlst.) Dahlst. $T$. sect. Erythrosperma. 45/ 515255 Seaton Carew, U:K. Sandy path. $2 n=24$. Obligate agamosperm. $N=38$.

Taraxacum sect. Vulgaria Au1. Serre Vebret, Saignes, Auvergne, France. Farm Lane, 750 m. $2 n=16$. Selfincompatible sexual. $N=28$.

Taraxacum sect. Vulgaria Au2. $7 \mathrm{~km}$ east of Champs sur Tarentaine, Auvergne, France. Turf in cottage garden, 800 m. $2 n=16$. Self-incompatible sexual. $N=75$.

Taraxacum sect. Vulgaria PL. Pont Lanau, Auvergne, France. Waste ground on camp site, 800 m. $2 n=16$. Self-incompatible sexual. $N=43$.

$N . B$. The three sexual populations from the Auvergne, France showed very considerable continuous morphological variation, and it was not possible to assign them to any species in the genus. This is a problem common to all sexual populations that can be placed in sections of the genus in which most populations are agamospecies, and the morphological species concept ("agamospecies") is necessarily narrow.

The following accessions were received as seed from single mothers except for SN. Studies on variability are perforce restricted to variation between seedlings which due to the breeding system are most probably full siblings.

Taraxacum aristum Haglund and Marklund. T. sect. Arctica. Lower Glenelg National Park, $38^{\circ} 00^{\prime} 25^{\prime \prime} \mathrm{S}$ $141^{\circ} 00^{\prime} 30^{\prime \prime} \mathrm{E}$, Victoria, Australia. Eucalyptus ovata and $E$. obliqua open forest with grassy understory on brown loamy sand with outcropping limestone N.H. Scarlett 84-466. $2 n=16$. Self-compatible sexual. "Arst".

Taraxacum bessarabicum (Hornem.) H.M. ( $T$. salsugineum Lam.). T. sect. Leptocephala. A single individual collected at St. Nectaire, Auvergne, France. Saline spring flushes at $700 \mathrm{~m}$, near the saline baths. $2 n=16$. Self-compatible sexual. "SN".

Taraxacum bessarabicum. Seed from Cluj Botanic Garden, Roumania. "Bess". 
Taraxacum bessarabicum. Seed from near Zaragoza, Spain. C.-I. Sahlin. "Sal".

Taraxacum serotinum (Waldst. and Kit.) Poiret. T. sect. Serotina. Seed from Macedonia, Greece (unlocalized). C.-E. Sonck. "Ser".

Taraxacum pyropappum Boiss. and Reut. $T$. sect. Serotina. Seed from near Zaragoza, Spain. C.-I. Sahlin. "Pyro".

Chromosome counts were made from root-tips taken from pot-grown plants, pretreated, fixed, stained and examined as described in Richards (1970). Breeding system behaviour was tested under glass in insect-free conditions. Self-incompatible sexuals invariably fail to set any seed unless cross-pollinated. If seed is set in these insect-free conditions, buds of young capitula of about $15 \mathrm{~mm}$ length, 3 to 4 days before anthesis are excised in such a way that the sigmas and anthers are removed and only the ovules remain. After this treatment, self-compatible sexuals set no seed. Obligate agamospecies set at least 90 per cent seed in successful (non-diseased) treatments.

Electrophoretic studies were based on leafextracts taken from young leaves of actively growing plants in pots under glass from January to June. Results are usually less satisfactory in the second half of the year when few new leaves are produced on mature plants. Enzymes were investigated on polyacrylamide gels with discontinuous non-dissociating buffer systems, using enzyme specific stains to visualize the resulting zymograms (Scandalios, 1969). Extraction techniques to deal with the special problems that Taraxacum poses, the systems studied, the allozyme loci characterized, and their mode of inheritance are described in Hughes and Richards (1985). For reasons stated there, esterase loci were excluded from analyses.

\section{RESULTS}

\section{Inheritance in agamosperm $\times$ sexual crosses}

A preliminary survey of isozymes in $T$. pseudohamatum revealed banding patterns and mobilities very similar to those in Aul for which inheritance tests had been made (see Hughes and Richards, 1985). The genetic control of isozymes in asexuals cannot be investigated except by hybridization with sexuals as mothers. It was considered important that the genetic control of isozymes in agamosperms, and the putative homology of these isozymes with genetically characterized isozymes in sexuals were studied in this way. As
Aul and Au2 plants that were used as mothers are fully self incompatible, iny seed arising from crosses with the asexual $T$ pseudohamatum should carry paternal genes. The morphological appearance of the hybrids, and the nature of their isozymes confirmed that all such seedlings were indeed hybrid. Two individuals of T. pseudohamatum and three of the sexual populations Aul and Au2 were used for crosses. Of many crosses attempted, only three set seed, at relatively low levels.

\begin{tabular}{llcl}
\hline Female (sexual) & $\begin{array}{l}\text { Male } \\
\text { (agamosperm) }\end{array}$ & $\begin{array}{l}\text { Number } \\
\text { of progeny }\end{array}$ & Code \\
\hline Au1. 30x & Ps 20c & 5 & $\mathrm{~S} \times \mathrm{A} 1$ \\
Au2. 49 & Ps 98a & 25 & $\mathrm{~S} \times \mathrm{A} 2$ \\
Au1.30y & Ps 20c & 9 & $\mathrm{~S} \times \mathrm{A} 3$ \\
\hline
\end{tabular}

Of the 39 progeny grown to maturity, 36 were diploid $(2 n=16)$ outbreeding sexuals. The other three were all eutetraploid $(2 n=32)$ and obligate agamosperms, setting 59, 82 and 99 per cent seed in isolation, and 55, 85 and 94 per cent seed respectively when emasculated. All three of these agamosperm offspring resulted from the first of these successful crosses, representing 3/5 (60 per cent) of the offspring of this cross.

All 39 progeny were assayed for the 9 enzyme systems ME, IDH, 6PGDH, GDH, CAT, PER, SOD, GOT and ACPH. For 17 progeny, MDH was also assayed. Parental zymograms for each of these systems, and the inheritance of the isozymes in the sexuals, were already known.

All 19 of the alleles observed in the sexual parents Au1 and Au2 also occurred in the agamospermous $T$. pseudohamatum parents, monomorphically, or as double banded or triple banded heterozygotes. Only one isozyme, termed CAT a', occurred in one of the $T$. pseudohamatum individuals but not in the sexuals. The isozymes of the parents, and the frequency of isozyme bands in the 39 progeny are shown in table 1 .

These results confirm that the sexual populations Au1, Au2 and PL, and the agamospermous population of $T$. pseudohamatum have genetically homologous loci and almost certainly the same allozymes, as the gene products show exactly the same electrophoretic mobilities. It is not possible to make a direct comparison between the sexual populations and $T$. unguilobum as the latter agamospecies always lacks pollen and cannot be used as a male parent in experimental crosses. No experimental crosses were made using the agamosperm $T$. brachyglossum as male parent. As will be seen, the isozymes of the inbreeding sexuals differ 
Table 1 Allele frequencies of allozymes in the parents and progeny of crosses between "French sexuals" and T. pseudohamatum, an agamosperm

\begin{tabular}{|c|c|c|c|c|c|c|c|c|c|c|c|c|c|c|c|c|c|c|c|c|}
\hline \multirow{2}{*}{$\begin{array}{l}\text { Locus } \\
\text { Allele }\end{array}$} & \multicolumn{2}{|c|}{$\mathrm{MDH}$} & \multirow{2}{*}{$\begin{array}{l}\mathrm{ME} \\
\mathrm{a}\end{array}$} & \multirow{2}{*}{$\begin{array}{l}\text { IDH } \\
a\end{array}$} & \multirow{2}{*}{$\begin{array}{l}\text { 6PGDH-1 } \\
\text { a }\end{array}$} & \multicolumn{2}{|c|}{ 6PGDH-2 } & \multirow{2}{*}{$\begin{array}{l}\text { GDH } \\
\text { a }\end{array}$} & \multicolumn{2}{|c|}{ CAT } & \multicolumn{2}{|l|}{ PER } & \multirow{2}{*}{$\begin{array}{l}\text { SOD-2 } \\
b\end{array}$} & \multirow{2}{*}{$\begin{array}{l}\text { SOD-3 } \\
\text { a }\end{array}$} & \multicolumn{2}{|c|}{ GOT-1 } & \multirow{2}{*}{$\begin{array}{l}\text { GOT-2 } \\
\mathrm{a}\end{array}$} & \multirow{2}{*}{$\begin{array}{l}\text { GOT-3 } \\
\text { a }\end{array}$} & \multicolumn{2}{|c|}{$\mathrm{ACPH}$} \\
\hline & a & $b$ & & & & a & $b$ & & $\mathbf{a}^{\prime}$ & a & a & b & & & a & b & & & a & b \\
\hline \multicolumn{21}{|l|}{ Plants } \\
\hline Aul $30 x$ & & & $1 \cdot 0$ & $1 \cdot 0$ & $1 \cdot 0$ & 0 & $1 \cdot 0$ & $1 \cdot 0$ & 0 & $1 \cdot 0$ & 1.0 & 0 & $1 \cdot 0$ & $1 \cdot 0$ & $1 \cdot 0$ & 0 & $1 \cdot 0$ & $1 \cdot 0$ & 0 & $1 \cdot 0$ \\
\hline Ps $20 \mathrm{c}$ & & & $1 \cdot 0$ & $1 \cdot 0$ & $1 \cdot 0$ & $0 \cdot 33$ & 0.67 & $1 \cdot 0$ & 0 & $1 \cdot 0$ & 0.67 & $0 \cdot 33$ & $1 \cdot 0$ & $1 \cdot 0$ & 0.67 & 0.33 & $1 \cdot 0$ & $1 \cdot 0$ & $0 \cdot 33$ & 0.67 \\
\hline offspring ( $n=5$ ) & & & $1 \cdot 0$ & $1 \cdot 0$ & $1 \cdot 0$ & $0 \cdot 19$ & 0.81 & $1 \cdot 0$ & 0 & $1 \cdot 0$ & $0 \cdot 81$ & $0 \cdot 19$ & $1 \cdot 0$ & $1 \cdot 0$ & 0.75 & $0 \cdot 25$ & $1 \cdot 0$ & $1 \cdot 0$ & $0 \cdot 25$ & 0.75 \\
\hline $\mathrm{Au} 249$ & $0 \cdot 5$ & $0 \cdot 5$ & $1 \cdot 0$ & $1 \cdot 0$ & $1 \cdot 0$ & $1 \cdot 0$ & 0 & $1 \cdot 0$ & 0 & $1 \cdot 0$ & $1 \cdot 0$ & 0 & $1 \cdot 0$ & $1 \cdot 0$ & $0 \cdot 5$ & $0 \cdot 5$ & $1 \cdot 0$ & $1 \cdot 0$ & $0 \cdot 5$ & $0 \cdot 5$ \\
\hline Ps 98a & 0.67 & $0 \cdot 33$ & $1 \cdot 0$ & $1 \cdot 0$ & $1 \cdot 0$ & 0.67 & 0.33 & $1 \cdot 0$ & $1 \cdot 0$ & $1 \cdot 0$ & 0.67 & $0 \cdot 33$ & $1 \cdot 0$ & $1 \cdot 0$ & 0.67 & 0.33 & $1 \cdot 0$ & $1 \cdot 0$ & $0 \cdot 33$ & 0.67 \\
\hline offspring ( $n=25$ ) & 0.5 & $0 \cdot 5$ & $1 \cdot 0$ & $1 \cdot 0$ & $1 \cdot 0$ & 0.96 & 0.04 & $1 \cdot 0$ & 0 & $1 \cdot 0$ & 0.98 & $\hat{0} \cdot 02$ & $1 \cdot 0$ & $1 \cdot 0$ & $0 \cdot 52$ & 0.48 & $1 \cdot 0$ & $1 \cdot 0$ & 0.44 & 0.56 \\
\hline Aul $30 y$ & & & $1 \cdot 0$ & $1 \cdot 0$ & $1 \cdot 0$ & $0 \cdot 5$ & $0 \cdot 5$ & $1 \cdot 0$ & 0 & $1 \cdot 0$ & $0 \cdot 5$ & $0 \cdot 5$ & $1 \cdot 0$ & $1 \cdot 0$ & $0 \cdot 5$ & $0 \cdot 5$ & $1 \cdot 0$ & $1 \cdot 0$ & $0 \cdot 5$ & $0 \cdot 5$ \\
\hline Ps $20 c$ & & & $1 \cdot 0$ & $1 \cdot 0$ & $1 \cdot 0$ & $0 \cdot 33$ & 0.67 & $1 \cdot 0$ & 0 & $1 \cdot 0$ & 0.67 & $0 \cdot 33$ & $1 \cdot 0$ & $1 \cdot 0$ & 0.67 & $0 \cdot 33$ & $1 \cdot 0$ & $1 \cdot 0$ & $0 \cdot 33$ & 0.67 \\
\hline offspring $(n=9)$ & & & $1 \cdot 0$ & $1 \cdot 0$ & $1 \cdot 0$ & 0.44 & 0.56 & $1 \cdot 0$ & 0 & $1 \cdot 0$ & $0 \cdot 5$ & $0 \cdot 5$ & $1 \cdot 0$ & $1 \cdot 0$ & $0 \cdot 5$ & $0 \cdot 5$ & $1 \cdot 0$ & $1 \cdot 0$ & 0.5 & 0.5 \\
\hline
\end{tabular}

significantly from those of the outbreeding sexuals Au1, Au2 and PL, and from T. pseudohamatum. However, for $T$. unguilobum and T. brachyglossum most of the isozymes showed the same mobilities as for Au1, Au2, PL and T. pseudohamatum, and for these it is assumed in the absence of other information that the same gene products are usually involved.

Table 1 shows that loci which are homozygous in the French sexuals Au1, Au2 and PL are often monomorphic (homozygous) in the agamosperm T. pseudohamatum as well. Correspondingly, loci heterozygous in the diploid sexual parents, such as $\mathrm{MDH}, 6 \mathrm{PGDH}-2$, PER, GOT-1 and $\mathrm{ACPH}$, with parental allele frequencies of 0.5 , are often heterozygous in the triploid agamosperm parent.

It is frequently assumed that polyploid agamospermous Taraxacum are allopolyploids, for instance from karyological evidence (e.g. Richards, 1972). Thus, it cannot be automatically assumed that every locus is trisomic in triploid $T$. pseudohamatum.

Attempts were made to confirm the hypothesis that heterozygous loci were present trisomically, i.e. that the more heavily staining band represented an allele that was present twice. Inheritance patterns in diploid offspring of crosses using individuals of hypothetical heterozygous genotype in $T$. pseudohamatum as males, tended to support the interpretation of genotypes based on differential band staining (table 4). It is likely that for all six loci at which $T$. pseudohamatum is heterozygous, the locus is present trisomically.

Heterozygous $T$. pseudohamatum should have either $a$ ab or $a b b$ at a locus. In most cases the difference in the intensity of staining of the bands in the double or triple banded heterozygotes indicated which genotype occurred, and this was borne out by inheritance patterns. Most offspring were diploid, and thus each parent contributed a single allele. Inheritance patterns suggest that alleles were inherited from triploid heterozygotes randomly in the majority of cases. However for 6PGDH-2 and PER in the cross Au2 $49 \times$ Ps $89 a$, an excess of homozygotes aa at a statistically significant level are found in the offspring. This does not seem to be the case for offspring of Ps 20c, heterozygous at the same loci.

For the three tetraploid offspring in the cross Au $130 x \times$ Ps $20 c$, it is assumed that the maternal (sexual) parent contributes a single genome, and the paternal (agamospermous triploid) parent contributes three genomes, although non-disjunction in the sexual female meiosis giving diploid eggs is also a possibility. In these cases, inheritance patterns confirm three-genome inheritance from the agamosperm.

\section{Comparison of isozyme variation between outbreeding sexual and agamospermous populations}

Isozyme data from wild populations of the three populations of diploid outbreeding sexuals from the Auvergne, Au1, Au2 and PL, and from the agamosperm populations of $T$. pseudohamatum, $T$. unguilobum and T. brachyglossum are presented in table 2 . Altogether 26 presumptive alleles at 15 loci in ten systems were studied. The locus TYR was not tested for inheritance between sexuals and $T$. pseudohamatum, although earlier test crosses between sexuals had shown normal Mendelian inheritance between these TYR alleles.

The following loci proved to be monomorphic in all sexual and agamospermous populations: IDH, GDH, SOD-2, SOD-3, GOT-2, and GOT-3. A single additional band occurred in one individual at the $\mathrm{ME}$ locus in the sexual population PL. This band, designated $M E a^{\prime}$ was not tested genetically as it did not occur in the test cross 
Table 2 Allele frequencies at 15 loci in six wild populations of sexual and agamospermous Taraxacum

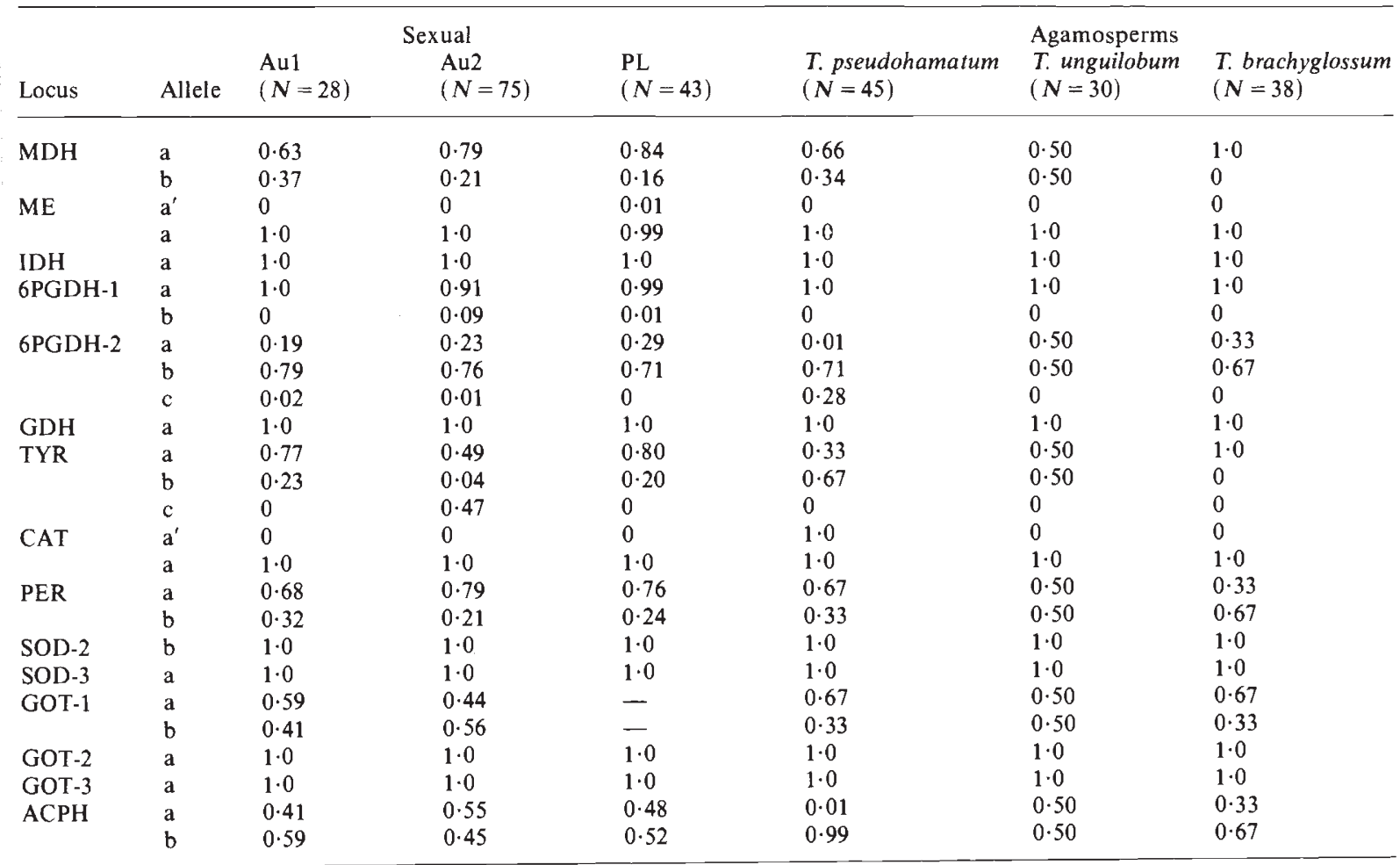

parents, but it has been tentatively interpreted as allelic to ME a. The locus 6PGDH-1 proved to be monomorphic in all three agamospermous populations, but a very few individuals carrying the rare allele 6PGDH-1 b occurred in two sexual populations. Of the agamosperms, $T$. brachyglossum proved to be monomorphic for MDH and TYR, although these varied in all other populations. For CAT, the sexual populations were monomorphic, as were the agamosperms $T$. brachyglossum and $T$. unguilobum; all the individuals of the $T$. pseudohamatum population displayed two bands at this locus. The band CAT a' is not inherited when $T$. pseudohamatum is crossed with sexuals, and on present evidence CAT a' cannot be regarded as being allelic to CAT a; it is not clear whether or not CAT is heterozygous in T. pseudohamatum; for the present it is regarded as being homozygous at two loci CAT a and CAT a'.

There are no loci amongst those studied which are monomorphic in the sexuals but polymorphic or heterozygous in the agamosperms. Viewing the data as a whole, there is a remarkable correspondence between the loci that are polymorphic in the sexuals, and those that are heterozygous in the agamosperms. There is also a remarkable corre- spondence for polymorphy in loci between the sexual populations, and for heterozygosity in loci between the agamospermous populations.

For seven polymorphic loci, the frequency of heterozygotes in the three sexual populations is consistent with the Hardy-Weinberg equilibrium in 20 tests $(6 \mathrm{PGDH}-1$ is not polymorphic in population Au1), except for ACPH in population Au1, where there is an excess of heterozygotes $\left(\chi^{2}=4 \cdot 3\right.$, $P<0 \cdot 05)$. In sexual self-incompatible outbreeders with large populations, Hardy-Weinberg equilibria would be predicted in the absence of significant selection or gene migration, so that it appears that these conditions are met in these populations. Indeed genotype frequencies generally show good fits to Hardy-Weinberg equilibrium expectancies; in $17 / 20$ tests significance levels for the $\chi^{2}$ test for non departures from expected frequencies exceed $P=0 \cdot 5$.

For the agamospermous populations, as predicted, the frequency of heterozygotes in polymorphic loci shows a very different picture (table 3 ). Six of the 15 loci studied are polymorphic in $T$. pseudohamatum and T. unguilobum. (The seventh locus which varies at a low level in the sexuals, 6 PGDH-1, is monomorphic in the agamosperms.) 
In T. brachyglossum, only four loci were polymorphic, MDH and TYR being monomorphic. Whereas, all the polymorphic loci in T. unguilobum and $T$. brachyglossum invariably occurred as (presumably fixed) heterozygotes, in $T$. pseudohamatum the situation was more complex. For three of the polymorphic loci, TYR, PER and GOT-1, only heterozygotes occurred. For MDH, only heterozygotes occurred, but the relative band staining suggested that one individual had the genotype abb rather than aab. Six progeny from this single individual, Ps 68 all clearly inherited this abb pattern of band staining which is found in no other parents or progeny of $T$. pseudohamatum. For ACPH, which is fixed heterozygously in $T$. unguilobum and T. brachyglossum populations, and which is polymorphic in all three sexual populations, only one heterozygous individual was discovered in the population of $T$. pseudohamatum. As for $\mathrm{MDH}$, six progeny from this individual ACPH heterozygote, which was also Ps 68, were tested, and all inherited the heterozygous banding pattern for this locus. For the 12 offspring of $\mathrm{ACPH}$ homozygotes that were tested, all were bbb homozygotes.

Three genotypes occurred in the $T$. pseudohamatum populations for 6PGDH-2, two of which were heterozygous abb and bbc and the third was homozygous for the $b$ allele. Only fixed aabb and abb heterozygotes were found in $T$. unguilobum and T. brachyglossum. Of the rare $T$. pseudohamatum 6PGDH-2 genotypes abb and $\mathrm{bbb}$, abb was once again confined to the single individual Ps 68 which had unique genotypes for $\mathrm{MDH}, \mathrm{ACPH}$ and 6PGDH-2. Six progeny of Ps 68 , and six of a parent with $6 \mathrm{PGDH}-2$ bbb genotype were examined for this system, and all were found to have the same genotype as their parents. In later tests, 25 progeny of a bbb genotype parent, and 31 progeny of a bbc genotype parent were tested for 6PGDH-2, and all were found to have parental genotypes.

As no other agamospermous individual of any species showed a unique genotype at any locus, the original individual Ps 68 and its progeny were closely examined morphologically. They could not be distinguished in any way from other members of the population, and taxonomically clearly could be assigned to $T$. pseudohamatum.

Various measures of genetic variation within and between the sexual and agamospermous populations are presented in table 5. There is no important difference between sexual and agamosperm populations for the proportion of loci that are polymorphic (P) within each population; only the lower proportion of polymorphic loci in the $T$. brachyglossum population is noteworthy.

There is a clear distinction between sexual outbreeding and agamospermous populations for the frequency of heterozygotes in a population, averaged over all loci (Het). For the three sexual populations, values for Het range from 0.13 to $0 \cdot 19$, but for agamospermous populations the range is 0.27 to $0 \cdot 40$. This is despite the fact that the proportion of polymorphic loci does not differ significantly between populations, and indeed there is a close correspondence between those loci that are monomorphic and those that are polymorphic, between sexual and agamospermous populations. Also, the mean number of alleles per locus, $A$, does not differ significantly between sexual and agamospermous populations. The difference in levels of heterozygosity, Het, between sexual and agamospermous populations is entirely due to the almost invariable tendency for polymorphic loci to be fixed as heterozygotes in agamospermous populations.

Heterozygosity, $H$, has been defined as Gene Diversity by Nei (1975), and as the Polymorphic Index by Marshall and Jain (1969). It is equivalent

Table 3 Frequencies of heterozygotes in polymorphic loci in three agamospermous populations

\begin{tabular}{|c|c|c|c|c|c|c|c|c|c|c|c|c|}
\hline \multirow{3}{*}{$\frac{\text { Locus }}{\mathrm{MDH}}$} & \multicolumn{4}{|c|}{ T. pseudohamatum $(N=45)$} & \multicolumn{4}{|c|}{ T. unguilobum $(N=30)$} & \multicolumn{4}{|c|}{$T$. brachyglossum $(N=32)$} \\
\hline & \multicolumn{2}{|c|}{ Genotype Number } & \multirow{2}{*}{$\begin{array}{l}\text { Frequency } \\
0.98\end{array}$} & \multirow{2}{*}{$\begin{array}{l}\text { Het. } \\
1 \cdot 0\end{array}$} & \multicolumn{2}{|c|}{ Genotype Number } & \multirow{2}{*}{$\frac{\text { Frequency }}{1 \cdot 0}$} & \multirow{2}{*}{$\begin{array}{l}\text { Het. } \\
1 \cdot 0\end{array}$} & \multicolumn{2}{|c|}{ Genotype Number } & \multirow{2}{*}{$\begin{array}{l}\text { Frequency } \\
1 \cdot 0\end{array}$} & \multirow{2}{*}{$\frac{\text { Het. }}{0}$} \\
\hline & $a a b$ & 44 & & & $a a b b$ & 30 & & & aaa & 38 & & \\
\hline \multirow[t]{3}{*}{ 6PGDH-2 } & $\mathrm{abb}$ & 1 & 0.02 & & aabb & 30 & $1 \cdot 0$ & $1 \cdot 0$ & $a a b$ & 38 & $1 \cdot 0$ & $1 \cdot 0$ \\
\hline & bbb & 6 & $0 \cdot 13$ & 0.87 & & & & & & & & \\
\hline & bbc & 38 & $0 \cdot 85$ & & & & & & & & & \\
\hline GOT-1 & $a a b$ & 45 & $1 \cdot 0$ & $1 \cdot 0$ & $a a b b$ & 30 & $1 \cdot 0$ & $1 \cdot 0$ & $a a b$ & 38 & $1 \cdot 0$ & $1 \cdot 0$ \\
\hline \multirow[t]{2}{*}{$\mathrm{ACPH}$} & $\mathrm{abb}$ & 1 & $0 \cdot 02$ & 0.02 & $\mathrm{aabb}$ & 30 & $1 \cdot 0$ & $1 \cdot 0$ & $a b b$ & 38 & $1 \cdot 0$ & $1 \cdot 0$ \\
\hline & bbb & 44 & 0.98 & & & & & & & & & \\
\hline
\end{tabular}


Table 4 Segregation of alleles at five polymorphic loci in diploid progeny of sexual $\times$ agamosperm crosses

\begin{tabular}{|c|c|c|c|c|c|c|c|c|c|}
\hline Locus & Cross & $\begin{array}{l}\text { Parental } \\
\text { genotype }\end{array}$ & $N$ & $\begin{array}{l}\text { Progeny } \\
\text { genotype }\end{array}$ & $E^{\mathrm{b}}$ & 0 & $x^{2}$ & d.f. & $P$ \\
\hline \multirow[t]{3}{*}{ MDH } & \multirow[t]{3}{*}{$\mathrm{S} \times \mathrm{A} 2$} & \multirow{3}{*}{$a b \times a a b$} & \multirow[t]{3}{*}{17} & aа & $5 \cdot 7$ & 4 & & & \\
\hline & & & & $a b$ & $8 \cdot 5$ & 9 & & & \\
\hline & & & & $\mathrm{bb}$ & $\begin{array}{l}2 \cdot 8 \\
(2: 3: 1)\end{array}$ & 4 & $1 \cdot 050$ & 2 & $0.7-0.5$ \\
\hline \multirow[t]{7}{*}{ 6PGDH-2 } & \multirow{2}{*}{$\mathrm{S} \times \mathrm{Al}$} & \multirow[t]{2}{*}{$b b \times a b b$} & \multirow{2}{*}{2} & $a b$ & 0.6 & 0 & & & \\
\hline & & & & $\mathrm{bb}$ & $\begin{array}{l}1 \cdot 4 \\
(1: 2)\end{array}$ & 2 & 0.857 & 1 & $0 \cdot 5-0 \cdot 2$ \\
\hline & \multirow{2}{*}{$\mathrm{S} \times \mathrm{A} 2$} & \multirow{2}{*}{$a a \times a b b$} & \multirow{2}{*}{25} & aа & $16 \cdot 7$ & $23^{\mathrm{a}}$ & & & \\
\hline & & & & $a b$ & $8 \cdot 3$ & 2 & $7 \cdot 159$ & 1 & $0 \cdot 1-0 \cdot 001^{* *}$ \\
\hline & \multirow{3}{*}{$\mathrm{S} \times \mathrm{A} 3$} & \multirow{3}{*}{$a b \times a b b$} & \multirow{3}{*}{9} & aa & $1 \cdot 5$ & 3 & & & \\
\hline & & & & $a b$ & $4 \cdot 5$ & 3 & & & \\
\hline & & & & $\mathrm{bb}$ & $\begin{array}{l}3 \cdot 0 \\
(1: 3: 2)\end{array}$ & 3 & $2 \cdot 000$ & 2 & $0 \cdot 5-0 \cdot 2$ \\
\hline \multirow[t]{6}{*}{ PER } & \multirow[t]{2}{*}{$\mathrm{S} \times \mathrm{Al}$} & \multirow[t]{2}{*}{$a a \times a a b$} & \multirow[t]{2}{*}{2} & aa & 1.4 & 2 & & & \\
\hline & & & & $a b$ & $\begin{array}{l}0 \cdot 6 \\
(2: 1)\end{array}$ & 0 & $0 \cdot 857$ & 1 & $0 \cdot 5-0 \cdot 2$ \\
\hline & $\mathrm{S} \times \mathrm{A} 2$ & $a a \times a a b$ & 25 & $\begin{array}{l}a a \\
a b\end{array}$ & $\begin{array}{c}16 \cdot 7 \\
8 \cdot 3 \\
(2: 1)\end{array}$ & $\begin{array}{c}24^{\circ} \\
1\end{array}$ & $9 \cdot 611$ & 1 & $0 \cdot 1-0 \cdot 001^{* *}$ \\
\hline & \multirow[t]{3}{*}{$\mathrm{S} \times \mathrm{A} 3$} & \multirow[t]{3}{*}{$a b \times a a b$} & \multirow[t]{3}{*}{9} & aa & $\begin{array}{c}(2.1) \\
3.0\end{array}$ & 2 & & & \\
\hline & & & & $a b$ & $4 \cdot 5$ & 5 & & & \\
\hline & & & & $\mathrm{bb}$ & $\begin{array}{l}1 \cdot 5 \\
(2: 3: 1)\end{array}$ & 2 & 0.556 & 2 & $0 \cdot 9-0 \cdot 7$ \\
\hline \multirow[t]{8}{*}{ GOT-1 } & \multirow[t]{2}{*}{$\mathrm{S} \times \mathrm{A} 1$} & \multirow[t]{2}{*}{$\mathrm{a} a \times \mathrm{a} a \mathrm{~b}$} & \multirow{2}{*}{2} & aa & 1.4 & 1 & & & \\
\hline & & & & $a b$ & $\begin{array}{c}0 \cdot 6 \\
(2: 1)\end{array}$ & 1 & $0 \cdot 381$ & 1 & $0 \cdot 7-0.5$ \\
\hline & $\mathrm{S} \times \mathrm{A} 2$ & $a a \times a a b$ & 25 & aa & $8 \cdot 3$ & 6 & & & \\
\hline & & & & $\begin{array}{l}a b \\
b b\end{array}$ & $\begin{array}{l}12 \cdot 5 \\
4 \cdot 2 \\
(2: 3: 1)\end{array}$ & $\begin{array}{r}14 \\
5\end{array}$ & 0.969 & 2 & $0 \cdot 7-0 \cdot 5$ \\
\hline & $\mathrm{S} \times \mathrm{A} 3$ & $a b \times a a b$ & 9 & aa & $\begin{array}{c}(2: 3: 1) \\
3 \cdot 0\end{array}$ & 3 & & & \\
\hline & & & & $\mathrm{ab}$ & $4 \cdot 5$ & 3 & & & \\
\hline & & & & $\mathrm{bb}$ & $1 \cdot 5$ & 3 & $2 \cdot 000$ & 2 & $0 \cdot 5-0 \cdot 2$ \\
\hline & & & & & $(2: 3: 1)$ & & & & \\
\hline $\mathrm{ACPH}$ & $\mathrm{S} \times \mathrm{A} 1$ & $\mathrm{bb} \times \mathrm{abb}$ & 2 & $a b$ & $0 \cdot 6$ & 1 & & & \\
\hline & & & & $\mathrm{bb}$ & $\begin{array}{c}1 \cdot 4 \\
(1: 2)\end{array}$ & 1 & $0 \cdot 381$ & 1 & $0 \cdot 7-0.5$ \\
\hline & $\mathrm{S} \times \mathrm{A} 2$ & $a b \times a b b$ & 25 & aa & $4 \cdot 2$ & 4 & & & \\
\hline & & & & $a b$ & $12 \cdot 5$ & 14 & & & \\
\hline & & & & $\mathrm{bb}$ & $\begin{array}{l}8 \cdot 3 \\
(1: 3: 2)\end{array}$ & 7 & $0 \cdot 394$ & 2 & $0 \cdot 9-0 \cdot 7$ \\
\hline & $\mathrm{S} \times \mathrm{A} 3$ & $a b \times a b b$ & 9 & aa & 1.5 & 3 & & & \\
\hline & & & & $a b$ & $3 \cdot 0$ & 3 & & & \\
\hline & & & & $\mathrm{bb}$ & $\begin{array}{l}4 \cdot 5 \\
(1: 3: 2)\end{array}$ & 3 & $2 \cdot 000$ & 2 & $0 \cdot 5-0 \cdot 2$ \\
\hline
\end{tabular}

\footnotetext{
${ }^{\text {a }}$ Homozygous excess.

${ }^{\mathrm{b}}$ Expected ratios: hypothetical genotypes based on differential staining (see text).

** Significant at 1 per cent level.
}

to the heterozygosity expected under panmixia; when mating is non-random, as with inbreeding and parthenogenesis, it is not related to the frequency of heterozygotes. Table 5 shows that estimates of $H$ for the sexual populations do not differ importantly from Het, confirming that genotype frequencies in these outbreeding populations for the polymorphic alleles investigated conform to Hardy-Weinberg equilibria. Similar levels of $H$ to those found in the sexuals also occur in the agamosperm populations; that is they are much lower than estimates for Het. In non-panmictic populations, $H$ will depend on parameters of the frequency of alleles in populations $(0.33$ and 0.67 for fixed triploid agamosperm heterozygotes) rather than frequencies of heterozygotes. It is not a particularly revealing statistic with respect to the genetic structure of non-panmictic populations. 
Table 5 Estimates of isozyme variation in three sexual outbreeding, and three agamospermous populations of Taraxacum

\begin{tabular}{|c|c|c|c|c|c|}
\hline & $\mathbf{P}$ & Het & $\mathbf{H}$ & A & G \\
\hline \multicolumn{6}{|c|}{ Sexual populations } \\
\hline Aul 1 & 40 & $0 \cdot 19$ & $0 \cdot 17$ & $1 \cdot 5$ & 0.96 \\
\hline Au2 & 47 & $0 \cdot 17$ & $0 \cdot 17$ & 1.6 & 0.98 \\
\hline PL & 50 & $0 \cdot 13$ & $0 \cdot 14$ & $1 \cdot 5$ & 0.95 \\
\hline \multicolumn{6}{|c|}{ Agamospermous populations } \\
\hline Ps & 47 & $0 \cdot 39$ & $0 \cdot 18$ & $1 \cdot 6$ & $0 \cdot 27$ \\
\hline Ung & 40 & 0.40 & $0 \cdot 20$ & $1 \cdot 4$ & 0 \\
\hline $\mathrm{Br}$ & 27 & $0 \cdot 27$ & $0 \cdot 12$ & $1 \cdot 3$ & 0 \\
\hline
\end{tabular}

P: percentage of polymorphic loci.

Het: heterozygote frequency per population over all loci.

H: $1-\sum x_{i}^{2}$; mean heterozygosity over all loci.

A: mean number of alleles per locus.

G: genetic diversity.

Figures for $A$, the mean number of alleles present in a population over all loci, do not differ significantly between the sexual and agamospermous populations.

Genetic diversity, $G$, is a measure of genotype diversity in populations, and is therefore a function of the frequency of individual genotypes in populations, as combinations of alleles within individuals, for all loci studied. It is estimated by $G=1-\sum g_{i}^{2}$ where $g_{i}$ is the frequency of the $i$ th genotype. For the sexual outbreeding populations, estimations for $G$ closely approach 1 , that is nearly all the individuals in the population have different genotypes with respect to the six loci that are always polymorphic. In fact, in Au1, three pairs of individuals share the same genotype; all the others are different. For Au2, one genotype is present in three individuals, and seven pairs of individuals share the same genotype. Of 75 individuals, 58 have unique genotypes. Of the 43 individuals in PL, 19 have unique genotypes and the same genotype does not occur in more than 4 individuals. For nearly all sexual individuals examined, the maximum number of genotypes possible for these six polymorphic loci is only $3^{6}=729$. By chance it should be expected that certain genotypes would be shared between individuals. It is likely that if more polymorphic loci were surveyed that all individuals in sexual outbreeding populations would prove to have different genotypes.

The genetic diversity of agamospermous populations is very different (table 5). For T. unguilobum and $T$. brachyglossum, all individuals in the study populations had the same genotypes for the 15 loci studied. For the T. pseudohamatum population, one individual (Ps 68) had a unique genotype for three different loci; a further six individuals shared a second genotype, and the remaining 38 were the same as each other (table 3 ).

\section{Isozyme variation in sexual inbreeders}

The sexual inbreeding accessions were not tested genetically with respect to allele inheritance. Many of the isozyme bands that were obtained with this material showed similar patterns of migration to those in the genetically tested sexual and $T$. pseudohamatum populations. Inbreeding plants were tested on the same gels as genetically characterized plants, and in all cases bands thought to be homologous with those in the genetically characterized plants showed identical migration. It was thought resonable to equate these with alleles identified in the sexual outbreeding populations. However, a number of new isozyme bands that did not occur in any of the sexual outbreeding or agamospermous populations were discovered in the inbreeders. These are termed $\mathrm{ME} \mathrm{b}$ and $\mathrm{c}$, IDH b, GDH b, PER c and d, SOD-2 a, SOD-3 b, GOT-1 c and d, GOT-2 c, GOT-3 b, and ACPH c and $d$. The new presumptive alleles represented in GOT-2 and GOT-3 were uniformly triple banded and did not segregate in the offspring, so they are regarded as monomorphic. It is emphasized that the new isozyme bands are not characterized genetically, so genotypes presupposed in table 6 must be regarded as somewhat speculative. However, band inheritance was tested in a second generation for all the sexual inbreeders, and presumptive homozygotes showed no genetic segregation.

It will be seen from table 6 that five of the accessions of sexual inbreeders were homozygous at all loci. For $T$. serotinum, two individuals were also homozygous, but one of the other two original seedlings was apparently heterozygous at the loci GOT-1 and ACPH, and the other at GOT-1. It is noteworthy that this accession of $T$. serotinum only set between 3 and 20 per cent seed in the absence of cross-pollination, and may therefore be partially self-incompatible (other inbreeding accessions set between 63 and 94 per cent seed in those conditions; sexual outbreeders never set seed). In only one further case was a locus observed to be polymorphic in these limited samples. The Roumanian accession of $T$. bessarabicum included seedlings with two different homozygous genotypes at 6PGDH-2. 
Table 6 Presumptive genotypes at 15 loci in six accessions of sexual inbreeders

\begin{tabular}{|c|c|c|c|c|c|c|}
\hline \multirow[b]{2}{*}{ Accession } & \multicolumn{3}{|c|}{ T. bessarabicum } & \multicolumn{2}{|c|}{$T$. section Serotina } & \multirow{2}{*}{$\begin{array}{l}\text { T. aristum } \\
\text { Arst }\end{array}$} \\
\hline & Sal & $\mathrm{SN}$ & Bess & Ser & Pyro & \\
\hline \multicolumn{7}{|l|}{ Locus } \\
\hline $\mathrm{MDH}$ & aa & aa & aa & aa & aa & $\mathrm{bb}$ \\
\hline $\mathrm{ME}$ & $\mathrm{cc}$ & $\mathrm{cc}$ & $\mathrm{cc}$ & $\mathrm{bb}$ & aa & $\mathrm{bb}$ \\
\hline IDH & aa & aa & aa & aa & $\mathrm{bb}$ & aa \\
\hline 6PGDH-1 & aa & aa & aa & aa & aa & aa \\
\hline 6PGDH-2 & aa & $\mathrm{cc}$ & $a a, b b$ & aa & aa & $\mathrm{bb}$ \\
\hline GDH & $b b$ & $b b$ & $\mathrm{bb}$ & aa & aa & $\mathrm{bb}$ \\
\hline TYR & $\mathrm{cc}$ & $\mathrm{cc}$ & $\mathrm{cc}$ & $\mathrm{bb}$ & aa & $b b$ \\
\hline CAT & aa & aa & aa & aa & aa & aa \\
\hline PER & $\mathrm{cc}$ & $\mathrm{cc}$ & $\mathrm{cc}$ & $\mathrm{cc}$ & $\mathrm{dd}$ & $\mathrm{cc}$ \\
\hline SOD-2 & aa & aa & aa & aa & aa & aa \\
\hline SOD-3 & bb & $\mathrm{bb}$ & $\mathrm{bb}$ & aa & $\mathrm{bb}$ & $\mathrm{bb}$ \\
\hline GOT-1 & $\mathrm{dd}$ & dd & $\mathrm{dd}$ & $a a, a b$ & $\mathrm{cc}$ & aa \\
\hline GOT-2 & $\mathrm{cc}$ & - & - & $\mathrm{cc}$ & aa & - \\
\hline GOT-3 & bb & aa & aa & $\mathrm{bb}$ & aa & aa \\
\hline $\mathrm{ACPH}$ & bb & $\mathrm{bb}$ & bb & $b b, b c$ & $\mathrm{cc}$ & $\mathrm{dd}$ \\
\hline Heterozygotes & 0 & 0 & 0 & 2 & 0 & 0 \\
\hline
\end{tabular}

In the second generation, all offspring genotypes were exactly parental, except for those derived from the parents of $T$. serotinum which were heterozygous at two loci (table 7). In the latter case, segregation occurred in the offspring with respect to these two loci, and consequently four offspring genotypes were detected.

Although the sexual inbreeders came from accessions from single mothers, it is possible to compute levels of $P$, Het, $A$, and $G$ with respect to the offspring families, although it is important to realise that these are not population measures, as they are for the agamosperms and the sexual outbreeders, and consequently it is not possible to obtain an estimate for $H$.

Table 8 shows that if these measures of genetic diversity are compared for sexual outbreeders, sexual inbreeders, and agamosperms, predictions as to the genetic structure of the populations or accessions with respect to the differing breeding systems are largely fulfilled. The inbreeding accessions show much lower levels of $P$, polymor- phic loci, and Het, heterozygote frequency than do either the sexual outbreeders or the agamosperms. These differences can be attributed to the effect of selfing in causing polymorphic loci to become fixed as homozygotes, although it must be realised that the samples of inbreeders were taken from a narrower genetic base (single accessions) than the outbreeders or agamosperms. The high figures for $A$, the number of alleles per locus, and $G$, genotypic diversity in the inbreeders, doubtless reflects the geographical and taxonomic diversity of the six inbreeding accessions. These come from sites as widespread as Spain, Greece and Australia, and are classified into four species placed in three sections of the genus. However, it is noteworthy that the genotypic diversity of the taxonomically and geographically closely allied sexual outbreeders is even greater than that of the sexual inbreeders. A high proportion of the individuals (siblings) within the sexual inbreeding accessions had the same genotype with respect to the 15 loci assayed.

Table 7 Genotype variation in two generations of sexual inbreeding accessions of Taraxacum

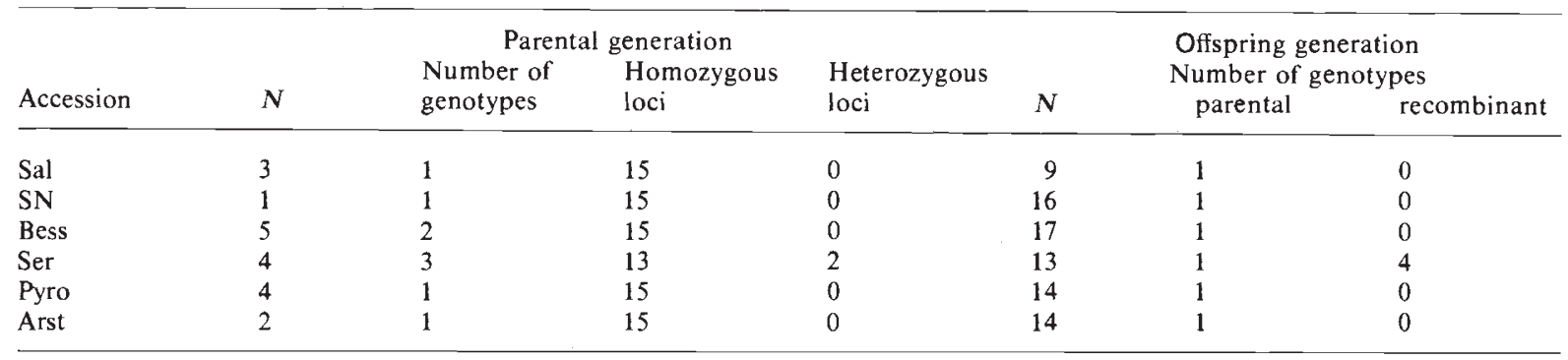


Table 8 Comparison between groups of Taraxacum with different breeding systems for various parameters of genetic variation as assessed by isozymes

\begin{tabular}{|c|c|c|c|c|c|c|}
\hline & $P$ & Het & $A$ & $G$ & $\begin{array}{l}\text { Number of } \\
\text { species }\end{array}$ & $\begin{array}{l}\text { Number of } \\
\text { populations/ } \\
\text { accessions }\end{array}$ \\
\hline Diploid outbreeders & 46 & $0 \cdot 16$ & $1 \cdot 5$ & 0.96 & (1) & 3 \\
\hline Diploid inbreeders & 20 & 0.01 & $2 \cdot 3$ & 0.85 & 4 & 6 \\
\hline Polyploid agamosperms & 38 & 0.35 & $1 \cdot 4$ & 0.09 & 3 & 3 \\
\hline
\end{tabular}

$P$ : percentage polymorphic loci.

Het: heterozygote frequency.

$A$ : mean number of alleles per locus.

$G$ : genotypic diversity.

\section{DISCUSSION}

Breeding system theory predicts that the genetic structure of populations of plants with differing breeding systems should differ widely. Sexual outbreeders should maintain genetic diversity within populations, and in these populations damaging linkage disequilibria and mutational loads should be advantageously dispersed, and gene migration and genetic recombination enhanced.

Sexual inbreeding and asexuality are very different breeding systems, yet they share some evolutionary advantages for plants. Female resource is limited to the production of fit genotypes very similar to the mother. Relatively little resource is spent on male function, or in producing "wasteful" males, and reproductive efficiency is high. The effect of inbreeding is to reduce the frequency of heterozygotes, with resultant high levels of allele fixation, and low levels of polymorphism. Thus, inbreeding populations should show low levels of heterosis, or high "inbreeding depression". However, inbreeders undergo recombination and segregation at meiosis, and such plants are able to disperse disadvantageous linkage groups by achieving levels of linkage equilibrium not dissimilar to those in outbreeding sexuals.

In contrast, most agamosperms are probably highly heterozygous, and the present study shows that obligate agamosperms are by virtue of heterozygous fixation twice as likely to be heterozygous at a locus as an outbreeding sexual, although no more likely to be polymorphic at a locus. It is likely that most obligate agamosperms are fixed hybrids. The resulting heterozygosity may allow agamosperms to show heterozygous advantage at many overdominant loci, giving "heterotic" hybrid vigour. However, agamosperms should have little if any recombination and segregation, and asexual lines should become severely disadvantaged in time by the mutations which accumulate in the genomes which act in effect as single linkage groups.

Previous studies which have compared the genetic structure of populations with differing breeding systems have largely confirmed these predictions, but in most cases have compared unrelated species with respect to different enzyme systems examined by different techniques. In the few cases where related plants with different breeding systems have been compared (de Arroyo, 1975; Schoen, 1982; Usberti and Jain, 1978; Levin, 1978) only two different breeding systems have been compared, differences between populations for breeding system tend to be relatively slight, and in no case are obligate asexuals investigated. The present study appears to be the first time that related outbreeding sexuals, inbreeding sexuals and obligate asexuals have been compared for the same enzyme systems, using the same techniques.

An examination of tables 5 and 8 shows how predictions are fulfilled for the populations of Taraxacum studied. There are no important differences within or between sexually outbreeding and agamospermous populations for levels of polymorphism. In contrast, the limited inbreeding samples show much lower levels of polymorphism, apparently as a consequence of allele fixation. The agamosperms are twice as heterozygous as the outbreeding sexuals, whereas the sexual inbreeders show very little heterozygosity at all. Nearly all sexual outbreeders differ from each other genetically. Two of the agamosperm populations show no genetic diversity in either generation. For the loci studied, all individuals are identical within a population. Within the third agamospermous population there is a low level of genetic diversity, but there is no variation between generations. For four of six inbreeding families there is no genetic variation between siblings in either generation, and 
for the other two levels of genetic diversity a re very low.

For these populations of Taraxacum, the predictions that sexual outbreeders should be polymorphic, fairly heterozygous and genetically highly diverse; that sexual inbreeders should have low polymorphism, should be largely homozygous and non-diverse; and that agamosperms should be polymorphic, highly heterozygous, but with scarcely any genetic diversity are well fulfilled. It is noteworthy however that totally asexual populations are not completely uniform genetically.

Acknowledgement Mrs Hughes was in receipt of an N.E.R.C. research studentship during the course of this work.

\section{REFERENCES}

ARROYO DE, M. T. K. 1975. Electrophoretic studies of genetic variation in natural populations of allogamous Limnanthes alba and autogamous Limnanthes flocculosa (Limnanthaceae). Heredity, 35, 153-164.

ASKER, S. 1979. Progress in apomixis research. Hereditas, 91, 231-240.

ASKER, S. 1980. Gametophytic apomixis: elements and genetic regulation. Hereditas, 93, 277-293.

FORD, H. AND RICHARDS, A. J. 1985. Isozyme variation within and between Taraxacum agamospecies in a single locality. Heredity, 55, 289-291.

GOTTLiEB, L. D. 1981. Electrophoretic evidence and plant populations. Progress in Phytochemistry, 7, 1-45.
HAMRICK, J. L., LINHART, Y. B. AND MITTON, J. B. 1979. Relationships between life history characteristics and electrophoretically detectable genetic variation in plants. Ann. Rev. Ecol. Syst., 10, 173-200.

HUGHES, J. AND RICHARDS, A. J. 1985. The inheritance of isozymes in sexual Taraxacum. Heredity, 54, 245-249.

LEVIN, D. A. 1978. Genetic variation in annual Phlox: selfcompatible versus self-incompatible species. Evolution, 32, 245-263.

LYMAN, J. C. AND ELLSTRAND, N. C. 1984. Clonal diversity in Taraxacum officinale (Compositae), an apomict. Heredity, $50,1-10$.

MARSHALL, D. R. AND JAIN, S. K. 1969. Genetic polymorphism in natural populations of Avena fatua and $A$. barbata. Nature, 221, 276-278.

MAYNARD SMITH, J. 1978. The evolution of sex. Cambridge.

NEI, M. 1975. Molecular population genetics and evolution. Amsterdam.

OOSTRUM, H. VAN, STERK, A. A. AND WIJSMAN, H. J. W. 1985. Genetic variation in agamospermous microspecies of Taraxacum sect. Erythrosperma and sect. Obliqua. Heredity, 55, 223-228.

RICHARDS, A. J. 1970. Eutriploid facultative agamospermy in Taraxacum. New Phytol., 69, 761-774.

RICHARDS, A. J. 1972. The karyology of some Taraxacum species from alpine regions of Europe. Bot. Jour. Linn. Soc., 64, 47-59.

RICHARDS, A. J. 1973. The origin of Taraxacum agamospecies. Bot. Jour. Linn. Soc., 66, 189-211.

RICHARDS, A. J. 1986. Plant Breeding Systems. London and New York.

SCANDALIOS, J. G. 1969. Genetic control of multiple molecular forms of enzyme in plants: a review. Biochem. Genet., 3, $37-79$.

SCHOEN, D. J. 1982. Genetic variation and the breeding system of Gilia achilleifolia. Evolution, 36, 361-370.

USBERTI, J. A. AND JAIN, S. K. 1978. Variation in Panicum maximum; a comparison of sexual and asexual populations. Bot. Gaz., 139, 112-116. 